\title{
ESTUDO DA DISTRIBUIÇÃO DE CALOR EM MODELOS COM PERDA DE CARGA NO PROCESSO DE DRENAGEM GRAVITACIONAL ASSISTIDA POR VAPOR
}

\author{
G. M. D. FERNANDES ${ }^{1}$, J. L. M. BARILLAS ${ }^{1}$ e T. V. DUTRA Jr ${ }^{1}$ \\ ${ }^{1}$ Universidade Federal de Santa Catarina, Departamento de Engenharia Química e Engenharia de \\ Alimentos \\ ${ }^{1}$ Universidade Federal do Rio Grande do Norte, Departamento de Engenharia de Petróleo \\ E-mail para contato: glydianne@gmail.com
}

\begin{abstract}
RESUMO - O processo SAGD (Steam Assisted Gravity Drainage) é largamente utilizado em alguns países com sucesso, como no Canadá onde existem inúmeros reservatórios de óleo com alta viscosidade. Alguns reservatórios do nordeste brasileiro apresentam características semelhantes sendo compostos também por óleo pesado. O processo SAGD tem início com a injeção contínua de vapor. Em seguida, uma câmara de vapor é formada em torno dos poços horizontais que cresce para cima e lateralmente à medida que mais vapor vai sendo injetado. Ao entrar em contato com o óleo frio, o vapor faz com que este aqueça e tenha a sua viscosidade reduzida. Esse contato faz com que o óleo condense e se dirija pela interface da câmara de vapor e, pela ação das forças gravitacionais, desça em direção ao poço produtor. Nesse estudo, a simulação numérica foi utilizada para analisar os efeitos das perdas de carga na distribuição do calor ao longo do reservatório, assim como a influência da quantidade de vapor injetada na produção acumulada de óleo.
\end{abstract}

\section{INTRODUÇÃO}

O processo de drenagem gravitacional assistida por vapor ("Steam Assisted Gravity Drainage") utiliza o mecanismo de produção natural devido à ação das forças gravitacionais. Neste processo são utilizados dois poços horizontais perfurados em paralelo e verticalmente um acima do outro, como mostra a Figura 1. 0 poço que injeta vapor é chamado de injetor e o poço que produz o óleo do reservatório é chamado de produtor. Esses poços possuem geralmente uma distância entre eles de $5 \mathrm{~m}$. A utilização dos poços horizontais no SAGD está relacionada à maior área de contato obtida em relação aos poços verticais, proporcionando uma rápida cobertura de todo o volume do reservatório, assim como uma maior recuperação.

O processo tem início com a injeção contínua de vapor. Em seguida, o poço injetor começa a injetar vapor no reservatório, uma câmara de vapor é formada em torno dos poços horizontais que cresce para cima e lateralmente à medida que mais vapor vai sendo injetado. Ao entrar em contato com o óleo frio, o vapor faz com que este aqueça e tenha a sua viscosidade reduzida. Esse contato faz com que o óleo condense e se dirija pela 
interface da câmara de vapor e, pela ação das forças gravitacionais, desça em direção ao poço produtor. Os espaços deixados pelo óleo removido vão sendo ocupados pelo vapor.

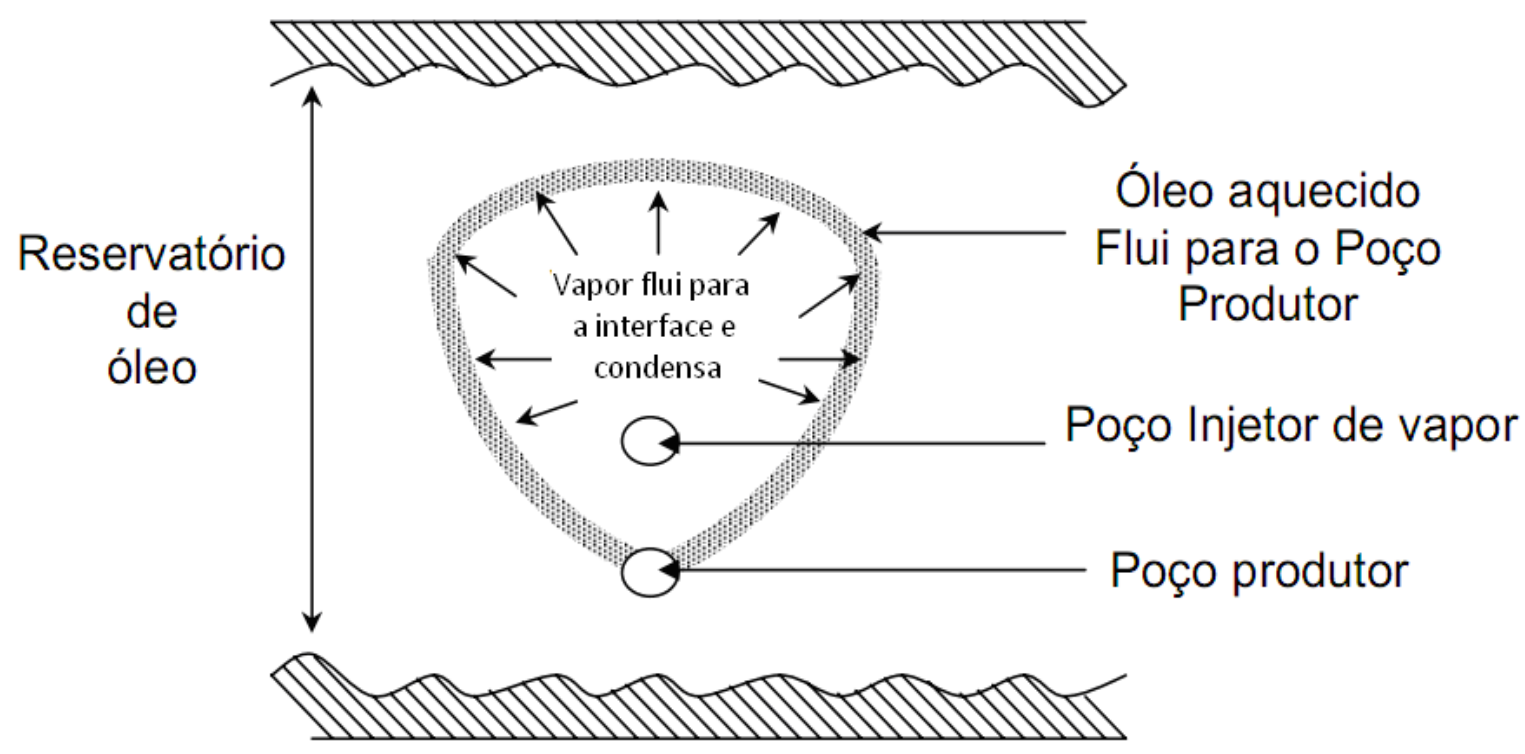

Figura 1 - O processo SAGD (Fonte: Tavallali, 2011)

No processo SAGD, a câmara de vapor se expande gradualmente e eventualmente permitindo a drenagem de uma larga área. 0 crescimento da câmara de vapor sofre primeiro uma limitação vertical ao atingir o topo do reservatório, em seguida ela continua seu crescimento lateralmente até os limites laterais do reservatório. 0 espaço antes ocupado pelo óleo é substituído pelo vapor.

A gravidade já está presente em todo o reservatório, e sendo usada como a principal força para o efeito do movimento do óleo. É possível evitar os caminhos preferenciais que ocorrem quando o óleo viscoso é movido e empurrado por um fluido menos viscoso. Outra vantagem é que o óleo permanece aquecido quando flui em direção ao poço produtor, ao contrário da injeção de vapor convencional.

Usando este método de recuperação, óleo pesado e betume podem ser utilizados de uma maneira sistemática através da obtenção de uma recuperação final maior que o processo de injeção de vapor convencional, em que o óleo é movido e empurrado pelos fluidos injetados.

O SAGD é mais efetivo para óleos pesados com alta viscosidade, ou para betume, sendo sua tecnologia muito utilizada devido ao alto fator de recuperação. Ele é aplicado atualmente no Canadá, Estados Unidos e na Venezuela, sendo um método adequado para reservatórios de pequena profundidade (Moreira, 2006).

Este trabalho teve como objetivo analisar a influencia das perdas de carga na distribuição do calor ao longo do reservatório, assim como a influência da quantidade de vapor injetada na produção acumulada de óleo. 


\section{9 a 22 de outubro de 2014 \\ Florianópolis/SC}

\subsection{Perdas de carga e calor nos poços do SAGD}

Poços horizontais são usualmente modelados sem considerar as variações de pressão e temperatura no poço. Essa aproximação assume que todas as células do poço se comportam similarmente, pressão, temperatura e vazão de fluxo de fluido são constantes dentro do poço, assim como trocas de calor e fluidos entre o poço e o reservatório. Essa aproximação constante de pressão e temperatura no poço tem bastante sucesso na maioria dos casos comuns apesar de ser hidrodinamicamente simplificado e correr o risco de superestimar a recuperação de óleo.

Na maioria dos casos complexos, com injeção de vapor, a aproximação anterior pode não ser adequada, uma vez que as variações de pressão e temperatura ao longo do poço alteram as trocas de fluidos e de calor entre o poço e o reservatório. Desta forma, quando as variações de pressão e temperatura são integradas ao modelo do reservatório a descrição do comportamento do poço se torna mais realista.

A perda de carga pode provocar uma distribuição não-uniforme do vapor nos poços, a formação de uma câmara de vapor não uniforme, uma efetiva redução no comprimento do poço, tendo como consequência uma redução na sua produtividade. Outro fator considerado é que quando a perda de carga existe a distribuição de vapor é alterada, resultando em um maior consumo de vapor, elevando os custos da geração de mais vapor (Thorne e Zhao, 2008).

A transferência de calor é o movimento da energia térmica de um local para outro. Há três maneiras nas quais a energia térmica é transportada: condução, convecção e radiação.

A condução térmica é responsável pelas perdas de calor para as camadas sub e sobrejacentes. A transferência de calor por convecção é o transporte de energia térmica através do movimento do fluido dentro de uma região de diferentes temperaturas. A transferência de calor por radiação é a transmissão de energia eletromagnética da superfície de um material no estado de vibração molecular; todas as substância irradiam esta energia eletromagnética. Durante o processo de injeção de vapor a radiação não é significativa dentro do reservatório.

\section{METODOLOGIA}

Nas simulações numéricas deste estudo, foi utilizado o simulador STARS (Advanced Process and Thermal Reservoir Simulator) da empresa CMG (Computer Modelling Group). 0 STARS é um simulador trifásico, de múltiplos componentes que tem como objetivo simular recuperações térmicas. Uma análise fatorial também foi realizada através do programa STATISTICA 7.0 para verificar quais parâmetros mais influenciam no aumento do fator de recuperação. Com base nesses resultados, a perdas de carga e a vazão de injeção de vapor foram os parâmetros mais significativos, parâmetros estes que serão analisados neste trabalho. 


\subsection{Modelo de Fluido}

Foi utilizado o modelo de fluidos "composicional" extraído de dados dos reservatórios da bacia potiguar. Nesse modelo, o tratamento matemático considera temperatura, pressão e as composições de diversas fases presentes no meio poroso. A Tabela 1 mostra a composição do fluido experimental utilizada neste modelo de simulação, onde existem 6 pseudo-componentes.

Tabela 1 - Composição do modelo de fluido experimental.

\begin{tabular}{cc}
\hline Pseudo-componente & \% Molar \\
\hline CO2-N2 & 0.72 \\
C1-C3 & 10.35 \\
IC4-C6 & 0.37 \\
C7-C20 & 20.59 \\
C21-C39 & 42.55 \\
C40+ & 25.42 \\
Total & 100.00
\end{tabular}

Só existem as fases água, óleo e gás. Não existem reações químicas envolvidas no processo e não existem sólidos nos fluidos a serem considerados.

\subsection{Modelo Físico do Reservatório}

0 modelo físico utilizado como base corresponde a um reservatório de $600 \mathrm{~m} \times 100$ m x $26 \mathrm{~m}$. 0 modelo possui dois poços horizontais um injetor e um produtor a uma distância de $13 \mathrm{~m}$ um do outro. Os poços possuem um comprimento de $510 \mathrm{~m}$ A Tabela 2 apresenta as propriedades do modelo.

Tabela 2 - Propriedades do reservatório

\begin{tabular}{cc}
\hline Propriedade & Valor \\
\hline Porosidade $(\%)$ & 30 \\
Permeabilidade Horizontal $(\mathrm{mD})$ & 1000 \\
Permeabilidade Vertical $(\mathrm{mD})$ & 100 \\
Saturação Inicial de Óleo $(\%)$ & 53 \\
Temperatura do Reservatório $\left({ }^{\circ} \mathrm{F}\right)$ & 100 \\
Contato água-óleo $(\mathrm{m})$ & 220 \\
\end{tabular}

Os parâmetros operacionais para o processo de simulação foram: pressão máxima no poço injetor de $7198,1 \mathrm{kPa}$ e a mínima pressão no poço produtor de $196,5 \mathrm{kPa}$. A temperatura do vapor foi fixada em $287,7^{\circ} \mathrm{C}$, o título do vapor em $50 \%$, a vazão máxima de injeção de vapor do modelo base foi de 100 ton/dia e a vazão máxima de produção no poço produtor foi de 500 $\mathrm{m}^{3} \mathrm{std} / \mathrm{dia}$. 


\section{RESULTADOS}

\subsection{Análise das perdas de carga e calor}

Foi realizada uma comparação entre os modelos com perda de carga e sem perdas de carga, para analisar a influência exercida pela perda de carga na produção acumulada de óleo e na vazão de óleo. A Figura 2 mostra a produção acumulada de óleo e a vazão de óleo versus o tempo. Não existem restrições na vazão máxima de produção para os dois modelos.

Observa-se que quando a perda de carga é considerada a produção acumulada de óleo se torna menor, devido aos efeitos da perda de carga e calor no poço injetor. Neste modelo, ocorre uma não uniforme distribuição do vapor, assim como perdas por fricção na injeção. Desta forma, o calor é perdido e pouco vapor chega até o final do poço, ao contrário do modelo que não considera a perda de carga. A vazão de óleo também é menor quando a perda de carga é considerada. A recuperação primária também foi inserida no gráfico para se observar o efeito suplementar que a injeção e vapor exerce em relação à recuperação através da energia natural do reservatório. Pode-se observar que no caso da recuperação primária, a produção acumulada de óleo é muito menor.

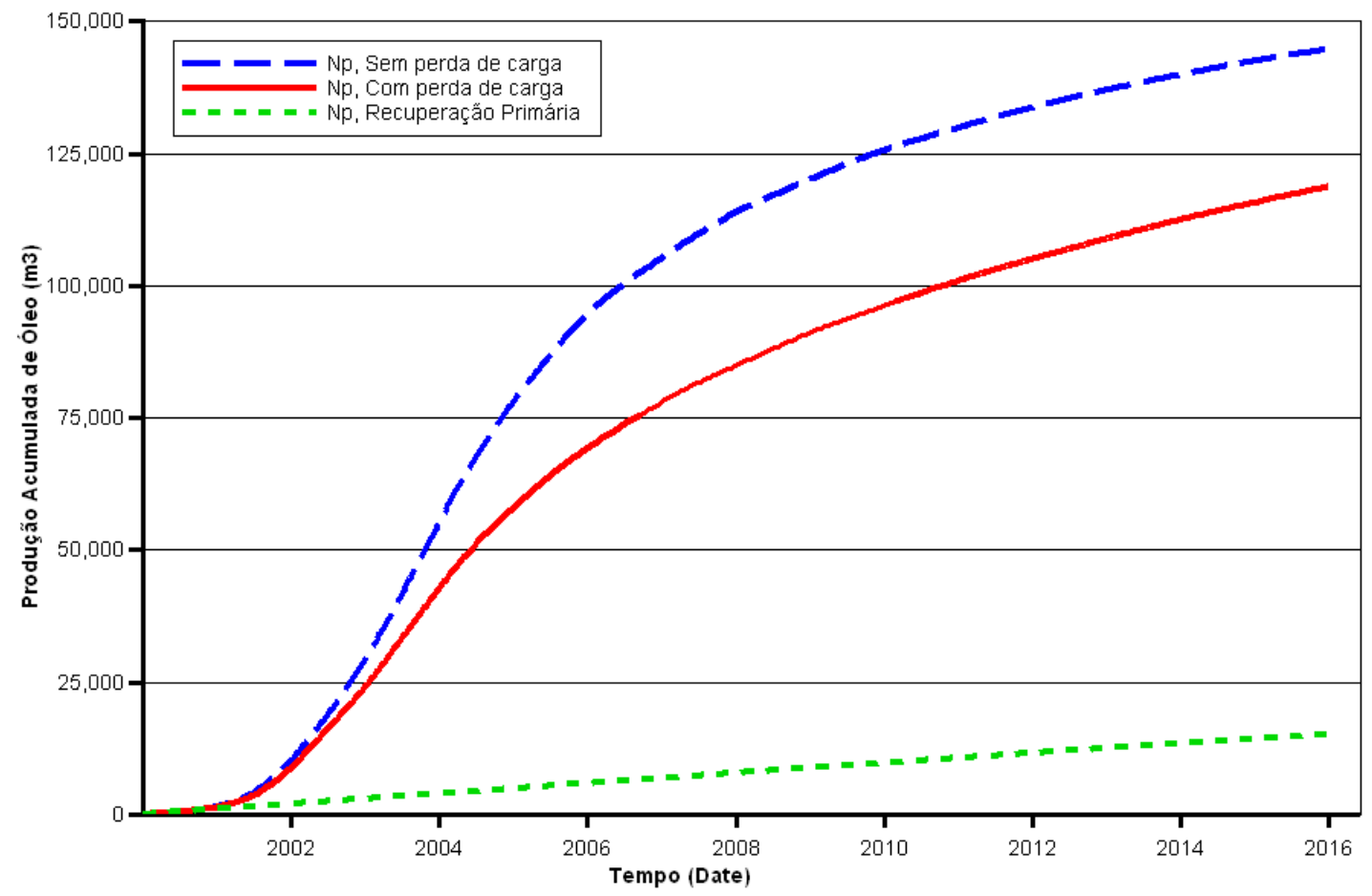

Figura 2 - Produção acumulada de óleo para os modelos com perdas de carga e calor, sem perdas de carga e calor e com recuperação primária.

A Figura 3 mostra a distribuição da temperatura para os modelos com e sem perdas de carga e calor. No modelo onde essas perdas não são consideradas, o vapor injetado aquece o reservatório de 
forma uniforme, fazendo com que o mesmo seja varrido por igual, aumentando assim a recuperação de óleo. Por outro lado, quando as perdas de carga e calor são inseridas no modelo há uma distribuição não uniforme de calor, fazendo com que apenas a parte inicial do reservatório tenha uma maior temperatura, como se observa a partir do quinto ano até o final do período de produção. Como o reservatório não é totalmente varrido, grande parte do óleo é deixado pra traz. Por esse motivo essas perdas precisam ser consideradas nos modelos de simulação tendo em vista que exercem influência no fator de recuperação.

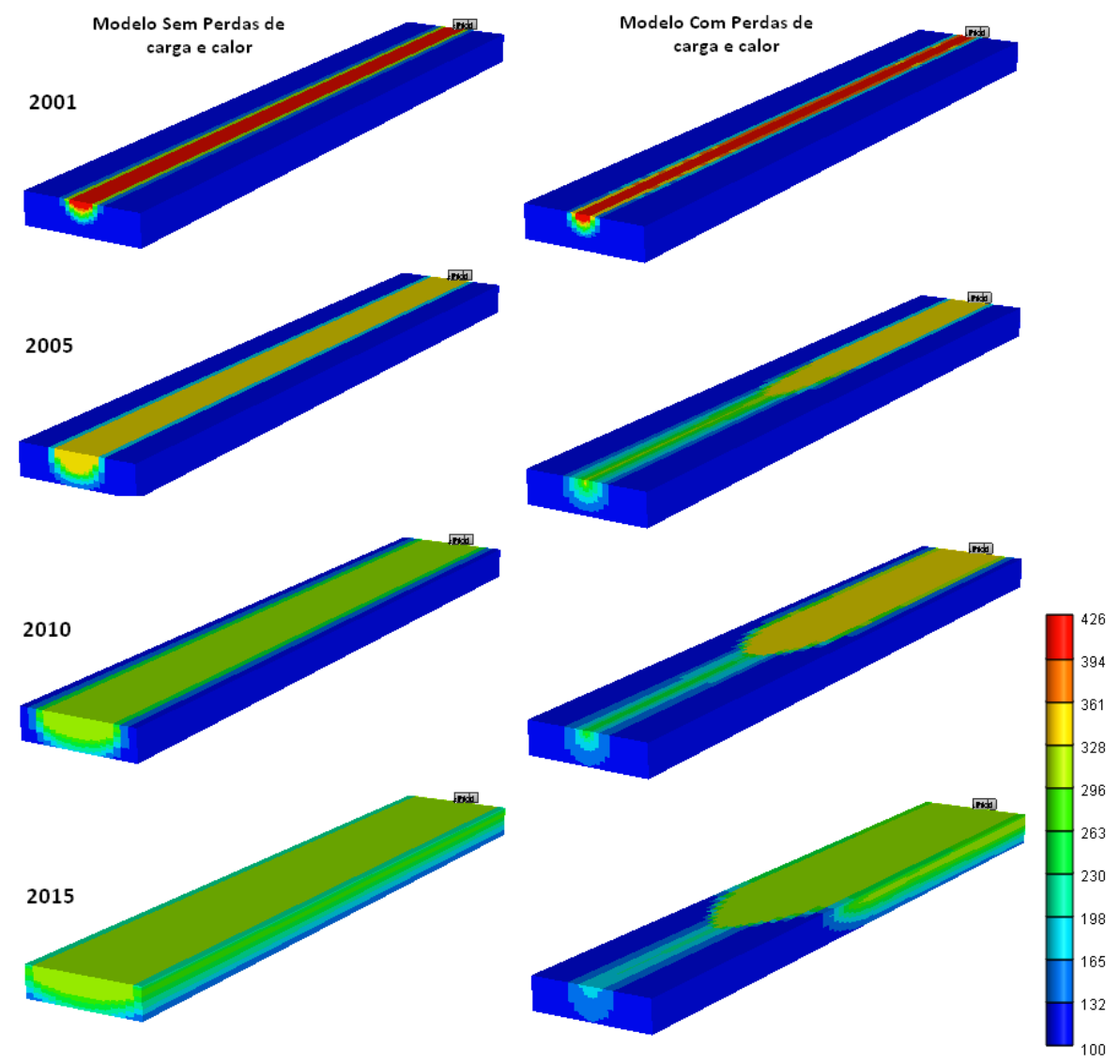

Figura 3 - Distribuição da temperatura para os modelos com e sem perdas de carga e calor.

\subsection{Análise da vazão de injeção de vapor}

Foi realizada uma análise do processo SAGD através da variação da quantidade de vapor injetada. A Figura 4 mostra a produção acumulada de óleo e a vazão de óleo para as vazões de injeção de vapor de 100 ton/dia, 200 ton/dia e 300 ton/dia. Quando se aumenta a vazão de injeção para 200 ton/dia há um incremento na produção acumulada e na vazão de óleo inicial. Por outro lado, quando a vazão de injeção foi de 300 ton/dia houve uma redução na produção acumulada de óleo devido ao vapor chegar mais rapidamente ao poço produtor, sendo então produzido no lugar do óleo. 


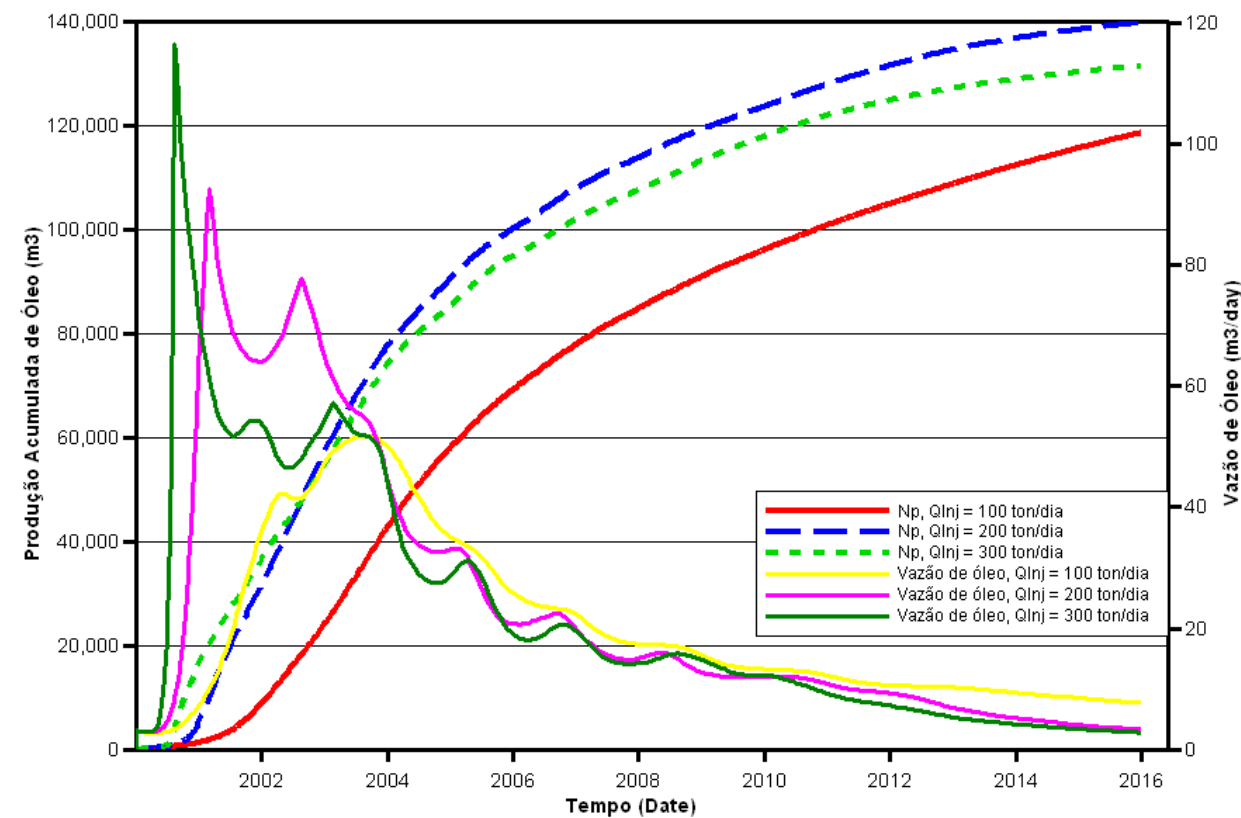

Figura 4 - Produção acumulada de óleo e vazão de óleo em modelos com perdas de carga e calor para as vazões de injeção de vapor de 100 ton/dia, 200 ton/dia e 300 ton/dia.

A Figura 5 apresenta a distribuição do vapor ao longo do reservatório durante os quinze anos de produção.

100 ton/dia

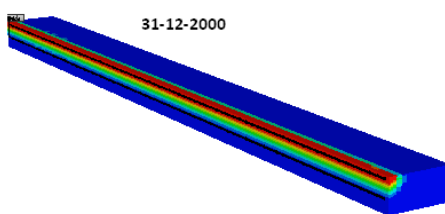

30-12-2007
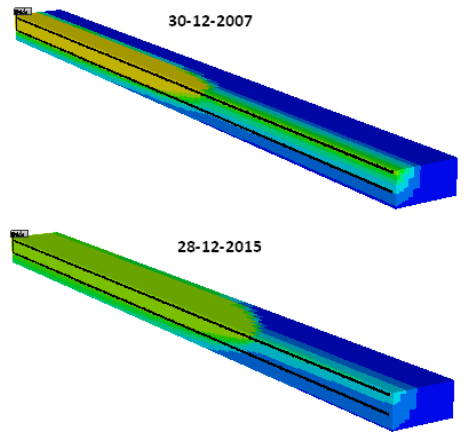

200 ton/dia
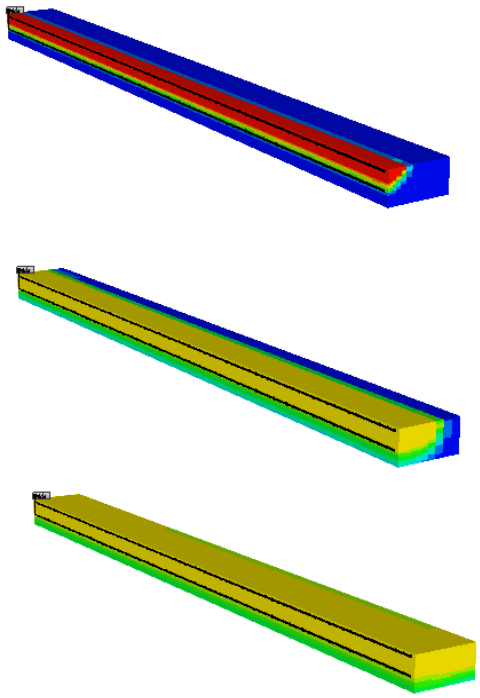

300 ton/dia
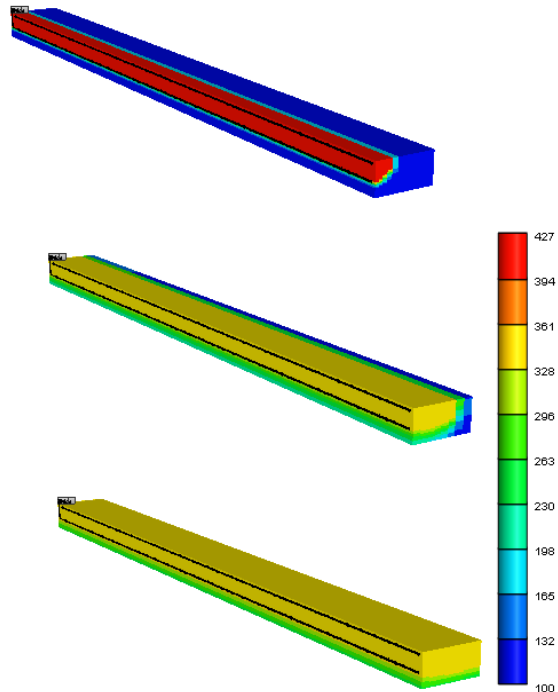

Figura 5 - Distribuição do vapor no reservatório para os modelos com vazões de injeção de vapor de: 100 ton/dia, 200 ton/dia e 300 ton/dia.

Inicialmente, a distribuição do vapor no reservatório acontece de forma uniforme para as três vazões de injeção de vapor, porém quanto maior a vazão maior a distribuição do vapor 
através da câmara. No sétimo ano de produção, observa-se uma distribuição não uniforme do calor para a vazão de 100 ton/dia devido aos efeitos das perdas de carga e calor ao longo do poço injetor. As vazões de 200 ton/dia e 300 ton/dia apresentaram uma distribuição de vapor similar. No último ano de produção, pode se observar o mesmo comportamento, sendo o modelo de vazão de 300 ton/dia o que obteve uma melhor distribuição do vapor, mas essa quantidade vapor faz o mesmo chegar mais rapidamente ao poço produtor. Desta forma, o modelo com vazão de 200 ton/dia apresenta o melhor resultado em termos de produção acumulada de óleo e de distribuição do vapor ao longo do reservatório.

\section{CONCLUSÕES}

De acordo com as simulações realizadas neste trabalho, pode-se concluir que:

- Quando a perda de carga é considerada a produção acumulada de óleo se torna menor, devido aos efeitos da perda de carga e calor no poço injetor.

- No modelo onde essas perdas não são consideradas o vapor injetado aquece o reservatório de forma uniforme, aumentando assim a recuperação de óleo. Por outro lado, quando as perdas de carga e calor são inseridas no modelo há uma distribuição não uniforme de calor, fazendo com que apenas a parte inicial do reservatório tenha uma maior temperatura.

- Observou-se que quanto à vazão de injeção de vapor foi aumentada de 100 ton/dia para 200 ton/dia houve um aumento na produção acumulada e uma melhor distribuição do calor no reservatório. Quando a vazão foi de 300 ton/dia houve uma pequena redução na produção devido a grande quantidade de vapor fazer com que este chegue mais rápido ao poço produtor.

- Recomenda-se uma análise futura das configurações dos poços do processo SAGD a fim de se obter uma otimização do processo. Além disso, um estudo mais detalhado sobre a energia gasta no processo pode ser fundamental para um melhor entendimento do processo.

\section{AGRADECIMENTOS}

Os autores querem agradecer ao apoio recebido da UFRN e do PRH-PB 21.

\section{REFERENCIAS}

MOREIRA, R. D. R. Injeção de vapor auxiliado por drenagem gravitacional em poço único. Dissertação de Mestrado, Universidade Estadual de Campinas, 178 p., Campinas, 2006.

STARS User's Guide, Advanced process and thermal reservoir simulator, Computer Modelling Group Ltd, 2007.

TAVALLALI, M. et al. Evaluation of New Well Configurations for SAGD in Athabasca McMurray Formation. SPE 143487. Maio, 2011.

THORNE, T.; ZHAO, L. The impact of pressure drop on SAGD process performance. SPE 2008 016. Junho, 2008. 